This item was submitted to Loughborough's Research Repository by the author.

Items in Figshare are protected by copyright, with all rights reserved, unless otherwise indicated.

\title{
Regenerative medicine, resource and regulation: lessons learned from the remedi project
}

PLEASE CITE THE PUBLISHED VERSION

http://dx.doi.org/10.2217/RME.10.89

PUBLISHER

(C) Future Medicine Ltd

VERSION

AM (Accepted Manuscript)

LICENCE

CC BY-NC-ND 4.0

REPOSITORY RECORD

Ginty, Patrick J., Erin Rayment, Paul C. Hourd, and David J. Williams. 2019. "Regenerative Medicine, Resource and Regulation: Lessons Learned from the Remedi Project”. figshare.

https://hdl.handle.net/2134/13379. 
This item was submitted to Loughborough's Institutional Repository (https://dspace.lboro.ac.uk/) by the author and is made available under the following Creative Commons Licence conditions.

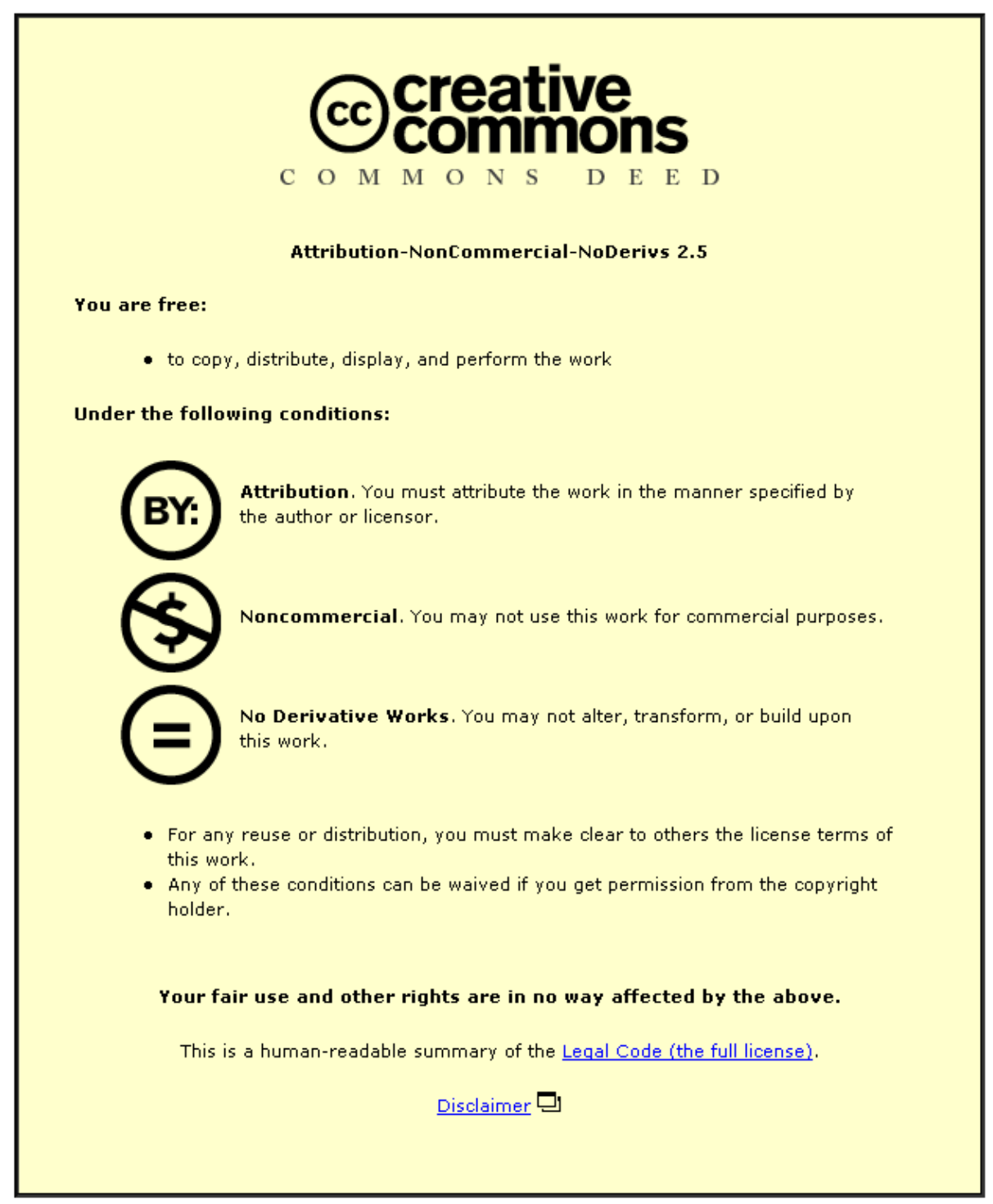

For the full text of this licence, please go to: http://creativecommons.org/licenses/by-nc-nd/2.5/ 


\title{
Regenerative Medicine, Resource and Regulation:
}

\section{Lessons Learned from the remedi Project.}

\begin{abstract}
Summary
The successful commercialisation of regenerative medicine products provides a unique challenge to the manufacturer due to a lack of suitable investment / business models and a constantly evolving regulatory framework. The resultant slow translation of scientific discovery into safe and clinically efficacious therapies is preventing many potential products from reaching the market. This is despite the need for new therapies that may reduce the burden on the world's healthcare systems and address the desperate need for replacement tissues and organs. The collaborative Engineering and Physical Sciences Research Council (EPSRC) funded remedi project* was devised to take a holistic but manufacturing-led approach to the challenge of translational regenerative medicine in the UK. Through strategic collaborations and discussions with industry and other academic partners, many of the positive and negative issues surrounding business and regulatory success have been documented to provide a remedi-led perspective on the management of risk in business and the elucidation of the regulatory pathways, and how the two are inherently linked. This paper represents the findings from these discussions with key stakeholders and the research into best business and regulatory practices.
\end{abstract}

\footnotetext{
*remedi is an EPSRC innovative manufacturing grand challenge designed to drive step changes in the capability, impact and excitement of UK manufacturing research through a consortium of academic and industrial stakeholders.
}

Venture Capital - GMP - Medical Devices - Adoption - Reimbursement 


\section{Scope}

The scope of the term Regenerative Medicine (RM) as used in this manuscript, has been defined by the industrial partners and collaborators that were consulted in the research and development of these findings. The majority of these companies were developing products that the authors of this manuscript have interpreted as having Regenerative Medicine (RM) applications, in that they either are being used or could be used, for the repair, regeneration or replacement of human tissue. These products came in two categories; (1) products composed of either; viable human cells or tissues for therapeutic use or (2) non-viable biomaterials that would form tissue repair scaffolds (medical devices). Therefore, this manuscript will refer to these products as RM products.

\section{Why is Regenerative Medicine Different?}

As an industry that reinvented itself in the wake of the failed tissue engineering "boom" of the 1990s, RM is still searching for the right formula that will bring significant healthcare benefits and resultant commercial success to the world's major markets. Evidence for this statement comes from the relative scarcity of viable RM products in the marketplace [1], especially considering the large amount of public and private money that has been invested in order to research and develop these products over the last 10 years. This is especially apparent in the US where companies such as Tengion and Geron have raised 100s of millions of dollars between them, even though neither yet has an FDA-approved product on the market [101-103]. In the UK, the situation is more worrying still, as there are currently no UK developed RM products beyond the clinical trials process, with little private investment available despite significant public funding into stem cell research [2][104]. The combination of these factors resulted in the simple conclusion that scientific discovery was not being 
translated into clinical and commercial success. This lack of translational success was the rationale behind the UK-based collaborative EPSRC-funded remedi project in 2005 [105].

One of the initial objectives of the remedi project was the identification of the unique challenges that makes the commercialisation of these living cell and tissue products different from conventional pharmaceuticals, in terms of manufacturing, financing and regulation. During its relatively brief history, tissue engineering, and then RM, has relied on many of the principles and business models that have proved to be successful in the more established healthcare industries such as pharmaceuticals or medical devices. However, unlike these well-established industries, which are characterised by the presence of large multi-nationals, $\mathrm{RM}$ is dominated by small to medium enterprises (SMEs), many from an academic environment that are operating in a high-risk, high-cost and relatively low investment space. Furthermore, this is compounded by a lack of legislative understanding in some areas, a result of the fast moving nature of the science and the ever evolving regulatory framework. Therefore, it is crucial that SMEs in the field of RM place significant emphasis on their early stage due diligence processes before beginning down the long road to commercialisation. We call this period "phase 0", as it comes before the product development process and represents an opportunity for a small business to prevent the use of precious resource on a commercially flawed technology, as well as allowing for the identification of areas of weakness within the business case. Equally, by providing evidence of this early stage assessment to investors, a significant amount of risk has been taken out of the equation, thereby making the business more attractive. The key to building a sound business case during phase 0 is the development of an in-house customer requirements document that indicates the key areas that should be addressed in order to satisfy those requirements. Even if investment has been sought successfully and the product development process has started in earnest, the principles of 
phase 0 must be taken forward with the number one priority being to continue to meet each customer's requirements and thus, reduce the risk of failure.

\section{The Importance of the Value Proposition}

Future success in the regenerative medicine field will depend on a SME's ability to manage risk, attract investment and achieve key technical milestones. In order to fulfil these goals, companies working in the RM space must satisfy the multiplicity of customers or stakeholders through the demonstration of value in the product and the parts of the business that are most relevant to each of them. It is essential that all of the potential customers for the business are identified, with the major requirements of each listed in Table 1 . The demonstration of value is best described as the value proposition (VP) which can be defined as 'the benefits offered to the customer, minus the cost and risk'. The VP is arguably the most vital part of the business case as it provides the framework for all of the other elements and addresses all of the customer requirements. There are three core elements to a successful VP; quality, safety and efficacy (in an addressable market), although there may be a dependence on maximising cost-effectiveness in certain markets. Demonstration of these three elements at key stages in the development of the business / product will provide evidence to investors that the business / product is commercially viable, thus reducing risk and enhancing the probability of a satisfactory return on investment (ROI). The most important milestones associated with gaining investment are; (1) the successful completion of animal proof of concept studies, (2) the completion of "first in man" or phase I clinical trials and (3) regulatory approval. These key value inflection points demonstrate safety (through successful human and animal studies) and quality (built into the process in the form of good laboratory practice (GLP) and good manufacturing practice (GMP)). Finally, regulatory approval shows that the major barrier i.e. Phase III clinical trials, have been successfully completed and that 
the product is sufficiently efficacious. Without any of these key value demonstrators, the company only has IP and in the field of cellular therapeutics, the true value of IP has yet to be determined.

Showing reimbursement value may be the most challenging part of the VP, as the requirements for efficacy and cost-effectiveness are relative to any incumbent technology and market size. Therefore, SMEs need to assess the relative efficacy needed to achieve cost effectiveness. This will determine both the reimbursement flexibility and acceptable cost of goods sold (COGS) and thus, determine the pricing structure and resultant ROI. New enabling technologies may be the key to reducing COGS that are driven by R \& D costs, such as the removal of bottlenecks from the manufacturing process or cheaper / faster testing methods. However, reducing COGS during the R \& D phase is challenging, as much of the costs are incurred through achieving regulatory compliance / approval and are therefore "nonnegotiable”. Due to this, emphasis will be shifted onto the efficacy of the product, placing a heavy burden on those SMEs that develop products to replace the current standard of care.

\section{Business Models: Product or Service?}

As things stand, RM companies that are looking to develop cellular products are largely left with the "do it yourself" (DIY) or "go it alone” model, as there are currently few buyers and exit strategies. This situation is largely due to the recent global financial crisis, followed by the lack of revenue streams for big pharma and subsequent downsizings. One example of this is Intercytex, where the idea was to take Cyzact, Intercytex's allogeneic wound- healing product, to market and sell it without partnering, as there was no interest from big pharma. Even though Cyzact did not ultimately get regulatory approval due to a failed Phase III trial, significant investment and growth was achieved over the life span of the company including 
the completion of a number of successful Phase I and II clinical trials [106]. However, it is likely that a new investment / business model will need to be created for RM products. Companies may now feel compelled to make RM more cost-effective by reducing COGS and thus pricing, such is the worry that they will not get sufficient investment or reimbursement, which are both discussed later in the manuscript. However, these are potentially high value products and should not be sold short.

Autologous therapies are viewed with some scepticism by investors as the real value is seen by many to still be in the process as there is a blurring between the product and the clinical procedure. This raises doubt over the actual role of a RM company in the field of autologous therapies. For example, many things affecting the value of the product (process) may be outside the control of the company, e.g. training healthcare professionals. This raises questions about the business model and the source of the ROI, as these products may more closely relate to a service-based offering. A commonly held perception, or perhaps misconception, is that autologous products can only fit into a service-based model as they are not traditional "off the shelf” products. However, autologous therapies can be products if they are branded as such. For example, Carticel® was branded as a product by Genzyme in the US and similarly ChondroCelect ${ }^{\circledR}$ is also being marketed as a product in Europe by Tigenix, despite both being autologous cartilage repair treatments that cannot be used off the shelf in the traditional sense. In addition, as well as the biological advantages of using cells from the same donor, autologous cells may offer a less complex route to providing a RM product as there may be less requirement for manipulation, because of the possibility of replacing them in the same surgical procedure. However, cell therapy products are costly to develop and manufacture, thus autologous products may not work in some contexts where large-scale, 
batch manufacturing processes are used as they do not have the same economy of scale as allogeneic therapies.

\section{Gaining Private Investment}

Before submitting a business plan or making a pitch to investors, a company must select and prepare thoroughly for investors who are active in the RM or biotechnology space, as they are more likely to be realistic in their expectations of the business. Even if a company is still at phase 0 , they should already be involved in a selling process in order to secure investment as soon as possible. The company also needs to understand what they are selling, as otherwise they will not gain the confidence of investors when making a pitch. In order to understand the product, it is important to understand the market, what the alternatives are and what price the market is prepared to pay. Whilst a strong pitch is essential, it must be assumed that the investor either understands, or has the capacity to understand, both the technical and the business concepts in equal measure. For example, it should not be assumed that the science is the difficult part and requires most of the brainpower and the business is of lesser importance. Therefore, if a scientist is to take the role of CEO in a small start-up company, they should be as good as a CEO / salesperson as they are a scientist.

There are three important components when negotiating with investors over the amount of cash required; (1) the value of the business and (2) the amount that you actually want to raise and (3) the financial status of the business. An overvaluation of the business will raise alarm bells in the mind of the investor and suggest that due consideration has not been given to the size of the market nor the costs of building a business, thus further increasing the risk. Equally, an underestimation of the company's value will place doubt in the mind of the investor with regard to their potential ROI and may result in the investor wanting a greater 
equity share than is desirable. Most new start-up and spin-out companies will be looking to raise private money on the back of some initial grant or seed funding and it is important to not let that money run dry before approaching private investors. This principle is the same during every funding round, as it important to negotiate from a position of strength i.e. nine months of money left in the business is better than three months of money left. Obviously, with private investors, the obligation is to produce a significant ROI, so there will be pressure from day one to meet milestones against progress.

Venture Capitalists (VCs) invest private funds that are raised from any number of limited partners [2]. Whilst all VCs are primarily interested in gaining the best ROI possible, it should be noted that there are varying time scales between VCs and their priorities might change over time. Most VC funds are 10-year life funds i.e. they last for 10 years from the start of the cycle. As a result, early stage deals i.e. those in the first three years of the cycle, are more likely as this is when the VCs are looking to invest most of their capital. Therefore, it is important to find out at when the fund cycle started. This 10 -year plan places enormous constraint on developers of cell therapies, as they are unlikely to commercialise their products in this time. Returns within this length of time are only likely to come from an acquisition or an initial public offering (IPO) i.e. through the DIY model, so there must be significant value built into the business plan within the first 10 years. It may also be diligent to approach the CEOs of companies that a potential venture fund has invested in, as they may be able to provide an insight into the suitability of a VC fund.

\section{$\underline{\text { Avoiding Cash Burn }}$}

In order to minimise cash burn in a small company, a constant review of human resources is required, especially important in the field of RM where investment is tight and the costs of 
development are relatively high. Initially, the CEO covers many roles, so it is best to hire additional staff incrementally and not to bring in expensive specialists too early. This form of lean development does present limitations, as with less money the business has to be more focussed and cannot over-diversify. In contrast, having more money available allows a company to "set more hares running" and gives them more chance of one being successful e.g. the big pharma model. However, this is a high-risk strategy for start-ups with limited resource, as the failure of a single product may prevent much needed resource being in place for the development of others. An example of this is Intercytex, where the cost of developing their lead product Cyzact ${ }^{\circledR}$ drew resource away from their large product pipeline, thus making these other products dependent upon Cyzact's success. Unfortunately, Cyzact was not successful and this ultimately resulted in the failure of Intercytex's "large pipeline" approach. Like large product pipelines, technology platforms can be very valuable in certain cases, but there must be a robust risk management process in place, as focus and diversification requires careful balancing.

Another way to avoid cash burn for university spin-outs is to remain in shelter for as long as possible. This way, much of the initial research and proof of concept work can be done using grant funding e.g. from sources such as the National Institute for Health (NIH) in the US, provided that IP rights are negotiated and there is sufficient value left for the business. Essentially, it is in the best interests of all of the stakeholders that the company is successful, so this negotiation should not result in a lack of agreement between the involved parties. It should also be remembered that the true value of much of the IP in RM, particularly in stem cell technologies as mentioned earlier, is yet to be established. Therefore, protecting IP should not come at the cost of the business - unless it is absolutely imperative and there are funds available to defend the IP if needed. There are limitations to staying in shelter as many 
commercial activities cannot be undertaken on certain grants that are intended to further academic research e.g. clinical trials and regulatory submissions. It should also be stressed that public sources of funding should only be used as a catalyst for growth and the generation of value in a business, they should not be seen as a way of taking a product to market. However, in addition to the development of IP, much of the pre-clinical due diligence for a potential new spin-out can be carried out within a University, such as early animal studies, an early assessment of the potential market and some investigation into the potential clinical utility of a new technology.

\section{The Regulatory Framework}

The regulatory requirements can be used to drive the innovation of new RM products, with those regulations that provide the least burden providing a faster route to market. For example, this may be due to reduced or in certain cases non-existent requirement to show safety and efficacy in clinical trials for Class II(a and b) (EU only), Class II (US only) and Class III medical devices (EU and US) (Figure 1). However, this is likely to change as the complexity and potential safety risk of devices increase to meet the clinical demand. The medical device pathways are not always relevant to RM and are limited in application as a device cannot contain viable cells or tissues, although there have been historical exceptions i.e. before the regulatory pathways for cellular products were clearly defined. However, there are still alternatives to the clinical trials route without the need to use the device pathways. For example, in the US there are three levels of regulation concerning cell- and tissue-based products, with the level of regulatory burden being proportional to the level of manipulation carried out and thus, the risk to the patient $[3,4]$. Those products that involve the removal and replacement of autologous cells or tissues within the same surgical procedure are not regulated under 21 CFR 1271 (Human Cellular, Tissue, and Tissue-based Products or 
HCT/Ps) and provide regulatory 'freedom'. The price for this freedom is that it becomes difficult to justify the need for a any commercial intervention when there is little or no processing or manufacturing required. The second level of regulation is for those products that are minimally manipulated, intended for homologous use, do not have a systemic effect, and include tissues other than bone marrow [5]. These are regulated as HCT/Ps) under Section 361 of the Public Health Service Act (PHSA). However, most HCT/Ps will not meet these strict criteria and will therefore be subject to the highest level of regulation; namely section 351 of the PHSA [5]. Under section 351, the HCT/P is subject to clinical assessment under an Investigational New Drug (IND) application before marketing approval can be granted through a successful Biologics License Application (BLA) [107]. This would include all allogeneic products unless they are for use in a first or second degree blood relative and fulfill the criteria for a section 361 product.

To take advantage of these regulations, a product that meets both a clinical need and avoids the definition of a 'section 351 product' would represent a fast track to market and require minimal risk and resource to do so. However, the business model would have to reflect this, as only autologous products can avoid section 351 (with the exception of allogeneic products from blood relatives described above) and this would move away from a traditional productled route and rely on a more service-based offering, although there is some blurring between the two in this field. In terms of manufacturing, the FDA regulations also require all companies involved in the manufacture of section 351 products for human application to be GMP-compliant (21 CFR 210 and 211), as well as meet applicable parts of 21 CFR 1271 for good tissue practice. However, 21 CFR Parts 210 and 211 were originally written for conventional pharmaceuticals, which means that they will work on a case-by-case basis for these regenerative therapies and will require a more creative approach by the developer. The 
unique challenges that these products provide demands that the developer has frequent interactions with the regulator throughout the process. Ultimately the regulator is a key customer and should be treated as such with any meetings carefully planned and attended by the correct personnel. For example, if the purpose of the meeting is to discuss technical issues, the regulatory agencies will want to speak to scientists and not marketing or other non-technical personnel.

In July 2008, the FDA issued new guidance intent on reducing the GMP burden, by exempting most products manufactured for phase I clinical trials from 21 CFR 211 [108]. However, this new regulatory guidance document made little reference to the manufacture of HCT/Ps, except for some limited recommendations on batch control and product testing. However, further draft guidance on GTP and GMP regulations for HCT/Ps that was published in January 2009 is still awaiting comment and may provide some additional information [107]. Perhaps even more significantly, a notice was published in the Federal Register in September 2009, indicating the FDA's intention to codify GMP requirements for combination products with specific reference to HCT/Ps. This is in recognition of the potential for many cell- and tissue-based therapies to be combined with a device or additional scaffold and the complications that this may bring to the manufacturing process.

Cell- and tissue-based products intended for human use are regulated as biological medicinal products in the EU under Directive 2001/83/EC, with additional provisions introduced via the Advanced Therapy Medicinal Products (ATMP) regulation, (EC/1394/2007). This regulation adds the definition of a tissue engineered product (TEP) to the existing definition of a somatic cell therapy (sCT) medicinal product already found in 2001/83/EC. Somatic cell therapy medicinal products are somatic living cells (autologous, allogeneic or xenogeneic) that have 
been substantially manipulated to attain a therapeutic, diagnostic or preventative effect through pharmacological, metabolic or immunological means. A TEP is one that contains or consists of engineered cells or tissues and is used for the regeneration, repair or replacement of human tissue. In order to meet the definition of an ATMP, a product must be substantially manipulated or not used for the same essential function in the recipient as in the donor. Any form of ex-vivo cell expansion is classed as a substantial manipulation but a number of other processes are not and they are listed in annex I of the ATMP regulation. If cell- or tissuebased a product is not considered to be substantially manipulated and is used for the same essential function in the patient as in the donor, it will be exempt from the ATMP regulation and regulated under the EU Cells and Tissues Directives (Figure 1). As a consequence of this, such a product will be exempt from the centralised market authorisation procedure (as described in EC/726/2004) required for all ATMPs and is therefore subject to regulatory oversight by the relevant national competent authorities. [6]. Directive 2003/94/EC outlines the principles of GMP of medicinal products, with much of the required guidance found in the annexes in Volume 4 of the EudraLex system, including annex II, which provides the specific guidance for biological medicinal products and is currently being updated to enhance the GMP guidance for ATMPs [7]. In terms of special requirements, ATMP manufacturers are obliged to provide full product traceability from product manufacturing to patient administration [6]. Again, the best way to ensure regulatory compliance is through a sustained interaction with the European Medicines Agency (EMA), which offers a number of incentives for SMEs developing ATMPs. For example, scientific advice can be sought throughout the development process, with a 90\% reduction in fees and a free certification service for quality and pre-clinical data can also be utilised in order to assist the transition from non-clinical to clinical studies. 
The clinical trials process is very different in the US and the EU and the regulatory pathways reflect this. Those wishing to carry out clinical studies in the EU must apply to the relevant competent authorities that operate within each individual member state of the EU in order to receive permission to commence a trial in that country. In the US, the regulations require the manufacturer to gain approval from both the FDA and an institutional review board (IRB) before a clinical trial involving a HCT/P can be commenced. An IRB is the US equivalent of an ethics committee in Europe; therefore IRBs are responsible for ensuring that the welfare and rights of patients are protected during clinical studies. However, the in the EU it must be remembered that each member state will have different ethics committees and different ethical viewpoints, so any potential multi-centre trial will have to be considered with this in mind, especially when ethically divisive technologies are involved in that trial e.g. human ES cells. One advantage in the EU clinical trials process in the EU is the new implementation of a clinical trials facilitation group (CTFG), which has been mandated to harmonise the clinical trials process across the EU, including harmonisation of the clinical trials assessment procedure between the different competent authorities in the EU [109]. Apart from the proliferation of regulations, patient numbers involved in the clinical trials process with these cell- and tissue-based therapies may also be dramatically less than in a traditional pharmaceutical product, and as such the clinical trial design is especially important. Companies may be limited to smaller data sets, and will need creative clinical study designs to gain maximum data from a smaller number of patients, combined with potentially higher costs for the study [4]. This remains an open issue in the design of clinical trials using viable human cells or any other complex biological product.

\section{$\underline{\text { Reimbursement and Adoption }}$}


Potential payers and healthcare economists should ideally be consulted during the business planning stage in order to provide some assurances that the product or treatment has reimbursable potential. Healthcare providers and payers will come in multiple forms dependent upon the selected markets but are likely to include a mixture of private and public payers that may operate with very different reimbursement models and thresholds. Effectiveness in an addressable market will be the first consideration of the payer but this will be relative to the current standard of care (if there is one) and the price they have to pay. Cost of goods sold (COGS) will directly impact on the pricing strategy for the product / treatment. Therefore, an assessment should be made of the costs incurred during each stage of the development and manufacture of the product or treatment. In addition to direct development costs, this calculation should take into account any third party involvement in the manufacturing process e.g. contract manufacturing or research organizations and any further implementation costs that will be incurred by the treatment e.g. training for healthcare staff, new equipment / facilities. However, as important as minimising COGS may be to the final pricing strategy, it is prudent for potential developers of RM products to look at meeting the un-met clinical need and placing the payer into a position where the demand for such a therapy or treatment would be overwhelming as this may negate any concerns over pricing and reducing cost.

In the US, the main government organization responsible for health care insurance and reimbursement is the Center for Medicare and Medicaid Services (CMS) [110]. With regards to new medical products, there are three key elements critical for reimbursement: coverage, payment and coding. Coverage refers to the payers' willingness to cover a product's proven clinical effectiveness in specified indications [8]. Payment relates to how much the payer is willing to pay for the product, and is currently calculated and paid for on a prospective 
payment system instead of on a cost basis [9]. This system provides a predetermined, fixed amount for care providers based on the procedure. Therefore, depending on the complexity of the situation, the amount reimbursed may not reflect the actual cost of treatment [9]. Reimbursement codes allow for the transfer of information between the physician and the payer and pertain to the treatment that was provided. Significantly, codes are specific to surgical and medical procedures, therefore, CMS has now begun to collect cost data on cell processing procedures [10]. There is of course a wide variety of public payers in the US e.g. Blue Cross, Cigna, etc. that will not necessarily use the same metrics as the government controlled payers, thus providing a variety of potential market entry points.

In Europe, there are a variety of private and public healthcare systems and payers and this requirement to negotiate multiple reimbursement pathways does reduce the attractiveness of the EU as a potential market. However, it does allow the developer of a RM product to have multiple attempts at gaining reimbursement and this can be an advantage as it is likely that each member state will use different metrics to assess new technologies, thus providing numerous other potential routes to market even after a negative opinion has been given. However, uptake in some member states may be significantly lower than in others and this is largely dependent on the type of healthcare system and the metrics that are used to judge new products. For example, in the UK, the National Institute for Health and Clinical Excellence (NICE) has a broad mandate to set standards for the use of new technologies and procedures within the National Health Service (NHS) [11] by following NHS's objective of maximising health gain from limited resources. Therefore, they assess new technologies on a number of factors, including: comparator technologies; economic evaluations; and measurement of health benefits in quality adjusted life years (QALYs) [12]. Cost-effectiveness is generally reported by an incremental cost-effectiveness ratio, which is the ratio of the expected costs to 
the expected QALY [12]. While there is no set limit for cost per QALY, NICE does tend to operate within a band of $£ 20,000$ - $£ 30,000$ per QALY, which may be reduced even further in current economic conditions, as the threshold above which it is likely to reject a technology on the basis of cost-effectiveness [11]. Unfortunately, this economic focus may restrict reimbursement for cell- and tissue-based therapies, as they are likely to be associated with high up-front costs, as well as requiring expensive patient-specific processing costs to be routinely covered in the case of autologous therapies [13]. However, this is not necessarily a unique case - NICE does currently reimburse in vitro fertilisation treatments for specific individuals, albeit dependent on the policy of the Primary Care Trust responsible for the patient's treatment [13].

Without favourable opinion from clinicians, the product or treatment is far less likely to be adopted / reimbursed by healthcare providers / insurers. Positive opinion at this early stage of the product / treatment life cycle may be reflected when clinicians are consulted by healthcare providers and reimbursement decisions are being made. Therefore, the clinical community should be consulted as early as possible during phase 0 to ensure that:

1. There is sufficient potential for clinical utility i.e. the treatment fills an un-met clinical need or it significantly improves on the current best treatment.

2. The proposed treatment / intervention is ethically sound.

3. There is some degree of clinical fit i.e. the treatment will not require a complete shift in the way that a surgical procedure is carried out or it makes the procedure more efficient.

Clinical adoption of innovative techniques and methods can be seen to involve three separate phases: exposure to information; the choice of clinicians to evaluate the innovation; and, the final learning process where both the people and the organisation 
successfully adapt procedures to use the innovation effectively [14]. In the current information age, it is often not the exposure of information that limits the adoption, but instead the choice and the learning phases [14]. Furthermore, the main factors critical for the technology's adoption are often seen as high patient demands, low training requirements and usage costs to the surgeon, as well as aggressive promotion of the technology by its manufacturer [15]. Following this, surgeon training and hospital construction needs to understand and acknowledge these RM products to enable wider technology adoption. For example, some cell- and tissue-based therapies may involve the need to manipulate cells close to the operating theatre where the tissue isolation takes place, which in turn requires cell processing facilities and trained staff in the same or nearby building. Government intervention may also be required to provide support for these new facilities, with hospitals already struggling to spend within their tight budgets and still provide a high quality of care. In the UK, there has been a large push for the NHS to actively support these cell-based treatments, not only as an early innovator, but also as a testing ground to translate these therapies from promising research into clinical applications [13].

\section{Managing Setbacks}

Managing setbacks is likely to be of fundamental importance to developers of RM products; such is the history of past failures and developmental barriers and the resultant cash burn that ensues. Issues with regulatory submissions are one of the most common setbacks, especially with regard to approvals for clinical trials. For example, Geron were initially placed on clinical hold by the FDA for deficiencies in their pre-clinical data for their GRNOPC1 hESC (human Embryonic Stem Cell) product for the treatment of spinal cord injuries [111, 112]. This was detrimental to Geron's value in the markets [113] but the lifting of that clinical hold 
should allow for a significant recovery. Conversely, UK-based stem cell company ReNeuron, have only had a fraction of the investment that Geron has received, despite also being involved in the development of a hESC therapeutic (RN001, for the treatment of stroke patients). When they were put on clinical hold by the FDA, ReNeuron moved quickly to seek clinical trials approval in the UK and was granted permission to start Phase I trials by the Medicines and Healthcare products Regulatory Agency (MHRA) [114]. Moreover, if the UK Phase I trial is successful and the products is shown to be sufficiently safe to progress to Phase II, there is also the possibility that the FDA may relax their own stance on RN001, thereby turning what was once a setback, into a positive outcome.

Not all setbacks are related to a lack of investment or regulatory approval. Organogenesis are the perfect example of a company that despite declaring bankruptcy in 2002, later became successful with a product (Apligraf ${ }^{\circledR}$ ) that is now reimbursed in the US and is likely to be launched in Europe within the next few years. However, one of the major contributing factors being cited for its original failure was a poor reimbursement strategy in the complicated US system [16]. Despite this, Organogenesis successfully came out of Chapter 11 in 2003 to relaunch Apligraf with a more robust reimbursement strategy that has resulted in healthy products sales and growth of the company [17]. Despite not being a rousing success on the scale of many pharmaceutical and biotech firms, all forms of success are relative and Organogenesis is the most successful company currently operating in the field of RM. They are also a good example of how a company can recover from a major setback, and that a bad experience can make you stronger, and does not necessarily mean the death of the company. For example, whilst the failure of Intercytex's lead product Cyzact during Phase III was far from a positive thing, Paul Kemp is now leading Intercytex as a limited company with a streamlined development strategy and a new focus. This has lead to the company gaining an 
orphan drug designation in Europe for the cell-based treatment of Epidermolysis Bullosa and a shift away from the US market for the time being to further focus the company [115].

\section{Conclusions}

The EPSRC-funded remedi project provided a unique opportunity to work with those in industry to both identify and provide solutions to, the issues that are most pertinent to the success or failure of the emerging RM industry. As part of this project, a work package was designed that focussed on the growth of both SMEs and the industry as a whole, whereby key business-related learning could be taken from key stakeholders and disseminated into the public domain. During this process, a number of key areas of concern were identified, most of which revolved around the lack of time and effort invested in the initial due diligence process undertaken by a new start-up or spin-out company before attempting to commercialize a new RM product. It is clear that companies developing RM products must look for innovative business models and commercial strategies and create a business case that includes key value adding steps that are both realistic and achievable. Without a solid value proposition that addresses the requirements of all the key customers of the business i.e. the regulator, investor, patient, payer and clinician, the developer is running the risk of using up precious time and resource on a product or technology that has significant commercial flaws and as a result, should not be taken through the development process. It is also essential that any company wishing to commercialise a RM product is acutely aware of the level of resource that is required to navigate the regulatory process (cost of quality and clinical trials) and where (a) resource can be saved and (b) assistance and advice can be sought from the regulatory agencies. Also fundamental to this due diligence process is the need to show that the product is likely to be sufficiently cost-effective, as those organisations that reimburse RM products will measure clinical impact against cost when making reimbursement 
evaluations. This does not imply that the product must be a blockbuster or carry a minimal price tag in order to get reimbursement, but there must be an addressable market that will permit the manufacturer to make money whilst also benefiting the healthcare system on a cost / benefit basis. Private investment in RM is scarce, and is more likely to come when value has already been generated in a business e.g. through regulatory approvals, efficacy data, etc. making the process of gaining that crucial initial investment even more difficult. This further emphasises the need for the early stage assessment of new RM products, as it will demonstrate to the investor that much of the risk has been removed or mitigated. The learning curve for companies operating in this field has been very steep and taken a number of casualties, but as those within the industry and academia gradually recognise the pitfalls of developing RM products and take more time to understand the mechanisms of investment, regulation and reimbursement, the greater their chances of commercial success.

\section{Future Perspective}

More than 20 years of hype over tissue engineering and regenerative therapies has masked the lack of success and certainty within the RM industry. However, reality has bitten and there now seems a consensus over the areas of uncertainty in the industry. As a result, the requirements for success should become clearer, especially in the UK where there are now many publically funded projects getting underway to resolve the business, regulatory and technical issues that are preventing these products from reaching market [116]. The regulatory landscape is ever evolving - there will never be a definitive set of requirements for RM due to the wide variability in product characteristics and their inherent risks. However, a greater understanding of the underlying science on the part of both the regulatory agencies and the developers of RM products will further elucidate challenging areas such as product characterisation [18]. Increased levels of confidence over the clarity of the regulatory 
landscape in the EU in particular may well lead to an increasing number of developers choosing to market in the Europe, with the ATMP regulation already having been road tested by Tigenix [117]. However, there will still be debate and limitations regarding which EU markets to choose to enter due to political, cultural and economic differences between member states. The continuing issues with gaining multiple favourable reimbursement decisions in the EU may also limit the uptake of RM products in certain countries, especially in those countries that operate under a strict cost-effectiveness regime such as the UK. As a result, the USA will remain an attractive market to developers of RM products in the EU as it is still perceived to be less problematic due to the dominance of private payers and the fact that it is technically classed as a single market; despite the need to achieve many positive local coverage decisions [19]. However, with the likely US healthcare system reform due to spiralling costs, it has been suggested that the Obama administration will follow the example of the UK and introduce similar technology appraisal process to that of NICE, thus potentially reducing the appeal of the US market to developers of RM products [118]. Perhaps the greatest changes over the coming years will come in the form of the business and investment models used by companies operating in the RM space. Greater knowledge and experience gained from dealing with the challenges of COGS, regulatory requirements and reimbursement mechanisms will allow individual companies to make more realistic assumptions regarding the financial feasibility of their technologies, which in turn may reduce some of the risk to potential investors. As a result of this, investors may be able to make more informed judgements regarding their choice of technology and to then structure their investment in such a way that it will maximise the benefit to both themselves and the company developing the product. However, this may require a change in the way that both the developer and the investor operate given the protracted time to profitability for these potentially high value products. 


\section{Executive Summary}

$\underline{\text { Scope }}$

- The scope of the term Regenerative Medicine (RM) as used in this manuscript, has been defined by the industrial partners and collaborators that were consulted in the research and development of these findings.

- The majority of these collaborators were developing products that the authors of this manuscript have interpreted as having Regenerative Medicine (RM) applications

- $\quad$ The products came in two categories; (1) products composed of either; viable human cells or tissues for therapeutic use or (2) non-viable biomaterials that would form tissue repair scaffolds (medical devices).

\section{Why is Regenerative Medicine Different?}

- The regenerative medicine industry is still searching for the right formula to achieve commercial success

- Despite significant fund raising efforts and scientific discovery there are very few regenerative medicine products on the market

- The EPSRC-funded remedi project was devised to take a holistic and collaborative approach to identifying many of the issues that act as barriers to commercialization and how they can be overcome

- Due to the high-risk nature of this emerging industry, small companies should carry out significant due diligence on their commercial potential before using precious resource and time on a product that is unlikely to succeed 


\section{The Importance of the Value Proposition}

- Small companies must satisfy a multiplicity of customers through the demonstration of value

- The demonstration of value is best described as the value proposition (VP), which is defined as 'the benefits offered to the customer, minus the cost and risk'

- $\quad$ There are three core elements to a successful VP; quality, safety and efficacy (in an addressable market)

- Showing reimbursement value may be the most challenging part of the VP, as the requirements for efficacy and cost-effectiveness are relative to any incumbent technology and market size

\section{Business Models: Product or Service?}

- A lack of buy-in from big pharma has left companies with no choice but to "go it alone” in many cases

- It is likely that a new investment / business model would have to be created for RM in order to remove some of the burden of taking a product into the clinic and beyond

- Companies now feel compelled to focus on cost-effectiveness and thus pricing, which could be detrimental as these are potentially high-value products and should not be sold short

- Autologous therapies may seem like a service-based offering, but many companies developing autologous therapies see them as products as they blend product and procedure 


\section{Gaining Private Investment}

- Companies should do their research and pick investors who are active in the RM or biotechnology space as they are more realistic in terms of their expectations

- Companies should know what they are selling, whom they are selling it to and must understand the market

- The CEO of a new start-up or spin out company should be as least as good a business man as they are a scientist

- Venture capitalists have a 10-year funding cycle and it is vital to know at which stage of the cycle they are at as it will affect the level of investment and the timelines for the ROI

\section{$\underline{\text { Avoiding Cash Burn }}$}

- Unnecessary staffing costs are one the easiest ways to burn cash in a new business and specialists should not be employed too early

- Large product pipelines are useful when attracting investors but they can drain resources and compromise the focus and quality of the development work

- University spin-out companies should remain in shelter for as long as possible to allow much of the important proof-of-concept and pre-clinical work to be carried out under grant funding

- Protecting intellectual property should not come at the cost of the business unless is it imperative the survival of the business and there are funds available to defend the IP if needed 


\section{The Evolving Regulatory Framework}

- The regulations can be used to drive the innovation of new RM products as there are opportunities to use the minimally-manipulated pathways, whereby clinical trials can be avoided

- $\quad$ The GMP regulations are currently being updated in the EU in order to provide a more complete set of manufacturing guidelines for developers of ATMPs

- The FDA relies heavily on guidance as many of the GMP requirements were written for conventional pharmaceuticals and are not applicable to HCT/Ps

- Interaction with the regulator is essential and the EMA provide many useful services to small companies including data certification and offer a $90 \%$ reduction in fees

\section{$\underline{\text { Reimbursement and Adoption }}$}

- Small companies should consult health economics and reimbursement experts during the business planning stage to help prevent technologies that are unlikely to be reimbursed from reaching the market

- Cost of goods sold will have a large impact on the pricing strategy for the company but achieving clinical effectiveness in an addressable market should still be the main focus of the treatment or therapy

- The US healthcare system is currently dominated by private payers where as many of the EU member states are dominated by government-led healthcare providers, especially in the UK where NICE technology appraisals are likely to limit the uptake of RM products 
- The key to adoption may be the early engagement of clinicians and key opinion leaders so that the technology can be influenced in order to gain better a better fit with current practices

\section{Managing Setbacks}

- Regulation has proven to be one of the major areas of difficulty for developers but the evolution of the regulatory framework and the introduction of new legislation is gradually reducing the burden

- Clinical trials involving hESCs are still proving difficult to initiate due to concerns over their safety but there is evidence that the regulatory agencies are becoming more experienced in dealing with these products

- Flawed reimbursement strategies have held companies back in the past but the reemergence of Organogenesis from chapter 11 to have commercial success has shown that such setbacks are not always terminal

- Large product pipelines are expensive to maintain and can place too much focus on the success of the lead product but streamlined development practices and smaller markets may provide an entry into the market provided there is sufficient clinical need

\section{Bibliography}

1 *Martin P, Hawksley R, Turner A: The commercial development of cell therapy - lessons for the future? Survey of the cell therapy industry and the main products in use and development. University of Nottingham, (2009).

2 * Prescott C: The promise of stem cells: a venture capital perspective. In: Advances in Tissue Engineering, Polak J,Mantalaris S,Harding S (Eds). World Scientific Publishing Company, London 491-500 (2008). 
${ }^{3}$ Burger S R: Current regulatory issues in cell and tissue therapy. Cytotherapy 5(4), 289-298 (2003).

${ }^{4}$ Preti R A: Bringing safe and effective cell therapies to the bedside. Nat. Biotech 23(7), 801804 (2005).

${ }^{5}$ Halme D G, Kessler D A: FDA Regulation of Stem-Cell-Based Therapies. N. Engl. J. Med 355(16), 1730-1735 (2006).

${ }^{6}$ European Union: Regulation (EC) No 1394/2007 of the European Parliament and of the council of 13 November 2007 on advanced therapy medicinal products and amending Directive 2001/83/EC and Regulation (EC) No 726/2004. L324/121-L324/137 (2007).

${ }^{7}$ European Agency for the Evaluation of Medicinal Products: Questions and answers on the regulation of advanced therapy medicinal products. (Doc. Ref. EMEA/14327/2009), (2009).

${ }^{8}$ Christian M, Martinson M: Getting Paid for All Your Hard Work: The Basics of Reimbursement for Healthcare Products and Services. Regulatory Affairs Focus, 5-10 (2002).

${ }^{9}$ Sood N, Buntin M B, Escarce J J: Does how much and how you pay matter? Evidence from the inpatient rehabilitation care prospective payment system. J. Health Econ 27(4), 10461059 (2008).

${ }^{10}$ Gajewski J, L. , Simmons A, Weinstein R et al.: The New Apheresis and Blood and Marrow Transplantation-Related Current Procedural Terminology Codes for Payment of Apheresis and Blood and Marrow Transplantation Services. Biol. Blood Marrow Transpl 11(11), 871-880 (2005).

${ }^{11}$ Pearson S, Rawlins M: Quality, Innovation, and Value for Money: NICE and the British National Health Service. JAMA 294(20), 2618-2622 (2005). 
${ }^{12}$ National Institute for Clinical Excellence: Guide to the Methods of Technology Appraisal. (2004).

${ }^{13}$ House of Commons Science and Technology Committee: Bioengineering - Seventh Report of Session 2009-10. (2010).

${ }^{14}$ Huckman R S, Pisano G P: Turf Battles in Coronary Revascularization. N. Engl. J. Med 352(9), 857-859 (2005).

${ }^{15}$ Wilson C B: Adoption of new surgical technology. BMJ 332(7533), 112-114 (2006).

${ }^{16}$ Bouchie A: Tissue engineering firms go under. Nat Biotech 20(12), 1178-1179 (2002).

${ }^{17}$ Lysaght M, Hazlehurst A: Tissue engineering: the end of the beginning. Tissue Eng 10(1/2), 309-320 (2004).

${ }^{18}$ Rayment EA \& Williams DJ: Mind the gap: challenges in characterizing and quantifying cell- and tissue-based therapies for clinical translation. Stem Cells 28(5), 996-1004 (2010). 19 *Ginty PJ, Singh, PB, Smith, D, Hourd, P, Williams, DJ: Achieving reimbursement for regenerative medicine products in the USA. Regen Med 5(3), 463-469 (2010).

\section{Websites}

${ }^{101}$ Department of Human Health and Services. 2020: A new vision, a future for regenerative medicine. http://www.hhs.gov/reference/newfuture.shtml. (Accessed May 2009).

102 Tengion inc. Press Releases. Tengion Inc. Completes \$50 Million Series "B" Round Financing led by Bain Capital and Quaker BioVentures will support neo-bladder clinical trials, manufacturing capacity and pipeline development, June 2006. http://www.tengion.com/news/press/20060623.cfm. (Accessed June 2009). 
${ }^{103}$ Feurstein A: Geron’s Stem-Cell Research Hype Soaks Investors. Genetics and Society, February 2009. http://www.geneticsandsociety.org/article.php?id=4533. (Accessed May 2010) ${ }^{104}$ Perrin NMR: The Global Commercialisation of Stem Cell Research in the UK: How can the UK's strengths in stem cell research be translated into commercial opportunities in a global market? http://www.chrismason.com/industry_library/assets/UKTI\%20Stem\%20Cell\%20Res.pdf. (Accessed April 2010). ${ }^{105}$ remedi: aims and objectives.

http://www.lboro.ac.uk/departments/mm/research/healthcare/remedigc/aims-objectives.html. (Accessed January 2010).

${ }^{106}$ Intercytex. Press Releases. Proposed placing of 23,076,924 shares at 52 pence per share raising £12 million, May 2007. http://www.intercytex.com/icx/news/releases/2007/2007-0503/index.html. (Accessed May 2009).

${ }^{107}$ US Food and Drug Administration: Guidance, Compliance and Regulatory Information. Draft Guidance for Industry: Current Good Tissue Practice (CGTP) and Additional Requirements for Manufacturers of Human Cells, Tissues, and Cellular and Tissue-Based Products (HCT/Ps), January 2009. http://www.fda.gov/BiologicsBloodVaccines/GuidanceComplianceRegulatoryInformation/G uidances/Tissue/ucm062693.htm. (Accessed January 2009).

${ }^{108}$ US Food and Drug Administration: Guidance for Industry; CGMP for Phase I Investigational Drugs, July 2008. http://www.fda.gov/downloads/Drugs/GuidanceComplianceRegulatoryInformation/Guidance s/ucm070273.pdf. (Accessed August 2008). 
${ }^{109}$ EU Heads of Medicines Agencies CTFG Activity Report, 2008-2009.

http://www.hma.eu/uploads/media/CTFG_activity_report_2008-2009.pdf. (Accessed July 2010).

${ }^{110}$ Centers for Medicare and Medicaid Services. http://www.cms.hhs.gov/. (Accessed July 2010).

${ }^{111}$ Geron inc. News Releases. Geron’s IND for Spinal Cord Injury Placed on Hold, August 2009. http://www.geron.com/media/pressview.aspx?id=1187. (Accessed May 2010).

${ }^{112}$ Geron inc. News Releases. Geron Receives FDA Clearance to Begin World's First Human Clinical Trial of Embryonic Stem Cell-Based Therapy, January 2009. http://www.geron.com/media/pressview.aspx?id=1148. (Accessed February 2009).

${ }^{113}$ San Jose Mercury News: Human tests of Geron's spinal-cord medication put on hold, August 2009. http://www.stemcellclinic.com/en/pr/item/700.html. (Accessed May 2010). ${ }^{114}$ Proinvestors UK: ReNeuron Group says clinical trial on hold, January 2007. http://www.proactiveinvestors.co.uk/companies/news/754/reneuron-group-says-clinical-trilon-hold-0754.html. (Accessed May 2010).

${ }^{115}$ European Medicines Agency. Press Release, November 2007. The EU and the FDA working together to create a Common Application for Orphan Designation for Medicines. http://www.ema.europa.eu/pdfs/general/direct/pr/55739107en.pdf. (Accessed May 2010). ${ }^{116}$ UK National Stem Cell Network Bulletin. Technology Strategy Board Regenerative Medicine Programme, September 2009.

http://www.uknscn.org/events/interim_ebulletin_2_sept2009.pdf. (Accessed May 2010). ${ }^{117}$ Tigenix. Press Releases, June 2009. Tigenix receives positive CHMP opinion on European MAA for ChondroCelect.

http://www.tigenix.com/en/objects/docs/newsroom/press_releases/2009/090626_TiGenix_Pr ess_Release_Pos_CHMP_opinion_EN.pdf. (Accessed March 2010). 
${ }^{118}$ Kerr DJ \& Scott M. British Lessons on Healthcare Reform. New England Journal of Medicine, September 2009. http://healthcarereform.nejm.org/?p=1702. (Accessed June 2010).

\section{Reference Annotations}

1 * Martin P, Hawksley R, Turner A: The commercial development of cell therapy - lessons for the future? Survey of the cell therapy industry and the main products in use and development. University of Nottingham, (2009).

This paper provides an interesting insight into the thoughts and opinions of those within the regenerative medicine industry.

2 *Prescott C: The promise of stem cells: a venture capital perspective. In: Advances in Tissue Engineering, Polak J,Mantalaris S,Harding S (Eds). World Scientific Publishing Company, London 491-500 (2008).

This article is of particular interest as it provides useful information on the mechanisms of venture capital investment as well as a venture capitalists perspective on the potential for the stem cell therapies.

19 *Ginty PJ, Singh, PB, Smith, D, Hourd, P, Williams, DJ: Achieving reimbursement for regenerative medicine products in the USA. Regen Med 5(3), 463-469 (2010).

This paper provides seeks to simplify the mechanisms of reimbursement in the US and is one of very few publications to focus on what is a very poorly understood but very important aspect of the commercialization of regenerative medicine products. 
- Patient

- Better clinical outcome

- Minimal cost

- Minimal hospital time

- Clinician

- $\quad$ Fewer interventions

- Better clinical outcome

- Minimal cost

- Clinical fit

- Longer shelf-life

- Regulator

- Fewer interventions

- Quality

- Safety

- Efficacy

- Payer

Positive risk:benefit profile

- Better clinical outcome

- Cost-effectiveness

- Minimal cost

- Longer shelf-life

- Fewer interventions

- Investor

- Market size/type

- First-in-man (Phase I) data

- Animal data, human efficacy data

- Regulatory approval

- Cost-effectiveness data

Table Legend

Table 1 likely customer (stakeholder) requirements for developers of regenerative medicine products. 


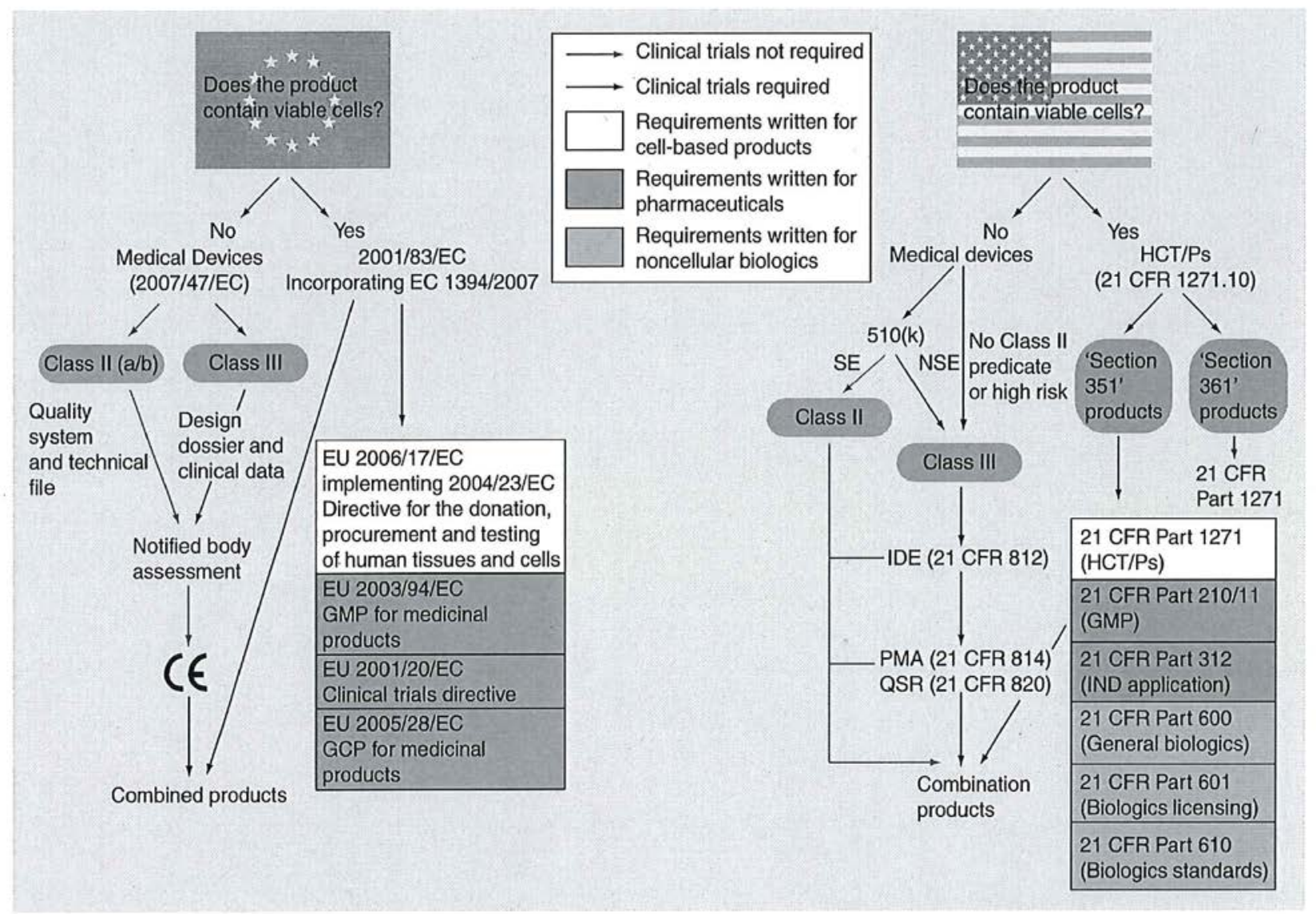

Figure Legend

Figure 1 Regulatory pathways showing the major legislative requirements for both cell- and device-based regenerative medicine products in the EU and the US. This illustrates the reduced regulatory burden for lower risk medical devices (Class II) when compared to higher risk devices (Class III) and the greater regulatory burden for cell- and tissue-based products that have been manipulated or used in such a way to present sufficient risk to require clinical trials and market authorisation i.e. section 351 products in the US and ATMPs in the EU). This figure also highlights the historical lack of specific regulatory legislation to cover the GMP and GCP requirements for biological products, a situation that is now being addressed by the regulatory authorities. 